\title{
Thinking temporally when thinking relationally: temporality in relational place-making
}

\author{
Amy Y. Zhang \\ School of Geography, Earth and Environmental Sciences \\ University of Birmingham \\ y.zhang.16@bham.ac.uk
}

\begin{abstract}
This paper engages with relational understandings of place and place-making, and highlights the importance of attending to the temporality of place-framing/making in analyzing place politics and place-making practices. Building temporary, strategic alliance is a key step of place-making in place contestations, however, there is so far limited attention paid to the impacts of such alliance building on place-framing/making practices, especially when different actors are positioned in uneven power relations. In this paper, I use a case study of the 798 arts district in Beijing, China to demonstrate that the need of gaining politically powerful actors as allies can have substantial influences on place-framing in the first place and on subsequent place-making results. Drawing on data collected from interviews and policy and planning documents, I show that in a framing of the 798 arts district constructed by artists for saving the arts district from being demolished, the art component of the arts district was concealed, whereas components of architecture, historical significance, and city image were strategically emphasized for gaining support from the municipal government. These elements were later incorporated into the municipal government's framings of arts districts through policies and planning, but were twisted and realigned with elements like tourism and experience, which ultimately facilitates displacement of artists from the arts district. Thus, I argue, relational approach towards placeframing/making needs to be more attentive to the temporality of place-framing/making, which would allow it to more sufficiently address how various citizen-state relationships shape placemaking and to become more globally oriented.
\end{abstract}

Key words place-framing, relational place-making, arts district, artists, Beijing, China

\section{Introduction}

Place and the framing of place are recognized by scholars as helpful points of entry for understanding and analyzing conflicts and the broader socio-spatial processes that such conflicts are part of. These conflicts may be about land use (the right or the way to use places) or about understandings of places (the look, feel, lived experience of places); and they may range from micro-scale locales (a specific site/place) to the scale of nation-building (Davine et al., 2017; 
Martin, 2003; Pierce et al., 2011; 2016; Van Neste and Martin, 2017). Although not all conflicts are at first explicitly concerned with place, it is often found that actors tend to express their concerns or claims through narratives of either the experiences in/of a place or the imagined ideal of a place (Martin, 2003). These discursive constructions of places - place-frames - are mobilized for collective actions and movements (place-making), within which (groups of) actors form temporary, strategic alliances based on their shared interests in/of a place (Martin, 2003; Van Neste and Martin, 2017). The co-articulation of place-frames and alliances of multiplypositioned actors requires a relational approach towards place-framing/making that explicitly focuses on "the interconnections and co-constituencies among place, networks and politics" (Pierce et al., 2011, 67; Van Neste and Martin, 2017).

This paper intends to enrich the relational place-making approach (Pierce et al., 2011) and argues for further attention paid to the temporality of place-framing/making. While existing literatures on relational place-making point out that actors who construct place-frames often need to go through negotiation or enrolling processes for gaining support from others or building alliance, these studies are insufficient in attending to how these negotiation and enrolling processes may affect place-framing in the first place and what the influences of enrolling new actors may be on existing place-frames and future place-framing/making. These aspects, I argue, are nevertheless important for understanding how places are relationally produced through networked politics, given uneven power relations among actors, and thus deserve proper attention. Specifically, in this paper, I demonstrate how the necessity of enrolling politically powerful actors affects place-framing/making in the first place and how the enrollment of such actors subsequently shape place-making, through a case study of the 798 arts district in Beijing, China. Thus, I argue that the temporality of place-framing/making reflects how the globally- 
varied citizen-state relationships shape place-making practices on the ground, and the relational place-making approach can be enhanced and become a more globally-oriented theorization ${ }^{1}$ by being more attentive to the aspect of temporality.

In what follows, I first provide the theoretic context through a review of the literatures on relational understandings of places and relational place-making. In this literature review, I highlight the key contributions of the relational place-making approach to studying place conflicts as well as point out existing research's lack of account of the impacts of enrolling actors on place-framing/making. I then discuss conflicts around arts districts both in and outside of China through the lens of relational place-making and demonstrate that in these cases, the necessities of enrolling politically powerful actors had significant influences on place-framing and place-making strategies and results. Building on this finding, the case study of the 798 arts district in Beijing provides a detailed account of how a place-frame of arts district is constructed by artists with the goal of gaining support from the municipal government and how this temporary artist-government alliance enables the municipal government to hijack the artists' place-frame and shape subsequent place-framing/making. I conclude by emphasizing that placeframes can be both narratives of (the martial, lived, or imagined) places and discursive strategies for negotiations with potential allies, and arguing for closer attention paid to how different moments (the anticipated future and the past) of place-making affect the strategies, practices, and results of place-making.

\section{Relational understandings of places and relational place-making}


Places, in relational understandings, are assemblages of heterogeneous elements that are constantly in the process of emerging and becoming, and "temporary constellations" or bundles of space-time trajectories configured through individuals' acts of selecting elements (Massey, 2005; Pierce et al., 2011; Pierce and Martin, 2015). Ontologically, at any locus, there are always multiple co-existing places, distinctively bundled by individual people; for any place, that is, a bundle whose identity is temporarily agreed/shared among a group of people, the alignment of elements is provisional and unstable. In other words, a "place", be it a city, a neighborhood, or a building, is always loaded with multiple meanings that are constructed from different sources and are subject to constant changes. Furthermore, these meanings, place-bundles, are produced through economic, social, and political interconnections that are constructed on multiple scales (Massey, 1991; 2005). Epistemologically, this ontological multiplicity and hybridity means that places can only be known partially (Pierce and Martin, 2015). One way of probing into the multiple facets of places is to gain access to and unpack some of the various meanings that a place assumes, by looking at discourses about the place, to tease out some of the bundles of space-time trajectories that overlap at one locus. The topology of these meanings, or bundles, is not one where they sit equally along with each other, but one that is characterized by competitions and contestations: an ongoing centering-decentering process that continually produces and reproduces places, namely place-making.

Place-making is political in nature. It is a process that involves (relatively) individually conceptualized and experienced place-bundles being drawn together and selectively expressed through place-frames towards social and political ends, which results in a "strategic sharing of place" (Pierce et al., 2011, 60). Place-frames, as discursive and rhetorical constructions, narrate places, either the material experiences or the imaginaries of them, for collective-action (Martin, 
2003; Van Neste and Martin, 2017). Thus, a place-frame rarely expresses one single placebundle or meaning, but consists of elements of multiple bundles that are selected through social and political negotiations among people with shared or similar goals (Pierce et al., 2011; 2016; Van Neste and Martin, 2017). It represents partially any of the place-bundles that are drawn into the place-frame, but itself is also a bundle among many others, albeit one that is constructed with explicitly strategic purpose.

Place-frames are mobilized by groups of actors in contestations over understandings and claims of places (Martin, 2003; Van Neste and Martin, 2017). These discursive constructions of places may convey actors' goals of place-making - to shape the use of places and/or to assert the right to use places. They are not separated from the material aspects of place-making, but are embodied in and manifested through material actions such as public protest, community organizing, and lobbying. Moreover, elements of place-frames can potentially be written into legally binding definitions of places through mechanisms like legislation, zoning, and official naming, hence can have considerable influence on the future of places (although official designations of places are always open to negotiations and place-making is always-ongoing). In order to achieve their place-making goals, actors may actively enroll others and seek wider and more politically powerful support (such as that of policy or law makers) to their place-frames (Pierce et al., 2016, 86; Van Neste and Martin, 2017). As the entangled processes of competitions among place-frames and negotiations for external support simultaneously unfold, one group's place-frame may become the (temporarily) dominant narrative and understanding of the place, or a new place-frame may be constructed through negotiations, drawing elements from multiple place-frames. The result is a place with temporarily agreed identity being produced through networked politics. 
Analyzing place-frames helps researchers examine the positionalities, goals, and strategies of actors in contested processes of place-making (Martin, 2003). Scholarship on relational place-making in particular articulates the relationship between the individual bundling processes and the socio-political positioning of places through place-framing, and especially emphasizes the necessity of focusing analytical attention on the bundles that are drawn into place-framing for examining place-based conflicts and right claims (Pierce et al., 2011; 2016). It then offers two major implications. First, by focusing on the bundles that inform different (groups of) actors' constructions of place-frames, it directs attention to identifying latent points of agreement and disagreement that might be obscured by place-frames mobilized by actors on opposing sides, thus opens up possibilities for alternative perspectives or resolutions. Second, by integrating relational understandings of place into discussions on the politics of place-making, it highlights the hybrid, multi-scalar, and temporary nature of any place-bundle, thus provides a means of intervention (Pierce et al., 2011; Pierce and Martin, 2015).

Existing relational place-making literatures offer an approach of studying place-based conflicts by starting with identifying key place-frames and actors, and then tracing back to some of the elements that constitute the place-frames that are in competition and the networks that actors are positioned in in order to locate key points of contestation and potential points of contention and commonality (Pierce et al., 2011; 2016). This approach points out that as placeframes that are constructed for collective goals do not include elements of all individually conceptualized place-bundles and since each actor is positioned in multiple networks, it is then possible for some of the actors who are on the opposite sides of a place-based conflict to have common elements in their place-bundles due to their shared networks. And by unpacking placeframes and examining positionalities of actors, this approach can reveal potential points of 
commonality in opposing actors' understandings of place and identify possibilities of bridging divides and fostering compromise (Pierce et al., 2011, 67).

The above approach, while pays attention to the relationship between individual placebundles and place-frames, lacks discussion on the processes of place-bundles being drawn into place-frames, namely how and why certain bundles and elements are drawn into particular placeframes and with what consequences. Although it can be said that place-frames are constructed on the basis of organizational and institutional interests, the processes would still involve strategically selecting elements and prioritizing certain rhetoric over others. And when the necessity of enrolling others for support is taken into consideration, the relationship between actors who construct place-frames and those who would be sought as supporters and allies would affect what elements are drawn into place-frames, and would further problematize the disconnection between individual conceptualizations and experiences of places and place-frames constructed for shared strategic goals. This complexity in the processes of place-framing has yet to be sufficiently accounted in scholarship on relational place-making. Such scholarship so far tends to treat place-framing and the processes of enrolling others into place-frames as two separate steps, without attending to whether and how the latter may affect the former either before (but anticipating) or during the enrolling processes (Pierce et al., 2016).

In their recent work on the dynamic processes of place-framing, Van Neste and Martin (2017) highlight the co-articulation of discourses and alliances of actors (network-building) in different moments of place-framing, and acknowledge that the power geometry of specific place politics can affect place-framing to a large extent (Van Neste and Martin, 2017, 11). Building on this latest endeavor in theorizing place-framing/making, I argue that to view the processes of place-framing relationally and to understand place-frames, like any place-bundle, as being 
temporary in nature means to consider not only how elements of individual place-bundles are selectively drawn into constructed place-frames, but also how processes on multiple scales and in multiple temporalities may simultaneously affect place-framing in an ongoing way - for example, knowing the necessity of enrolling certain actors may affect the construction of place-frame in the first place and the negotiation processes for enrolling such actors may subsequently alter the place-frame. This latter aspect is currently inadequately discussed in literatures on relational place-making, but in practice could have significant influence on places and all actors who are involved in place-making. This paper contributes to filling this gap in the literature by focusing on how place-frames are constructed when the necessity of gaining the support of politically powerful actors is taken into consideration and how such strategy affects the results of placemaking, through a case study of one arts district in China.

\section{Place-making in the case of arts districts}

In this section I focus on place-framing/making strategies of artists in two situations: one is artists' conflicts with landlords during early development of arts districts in China, and the other is SoHo artists' advocacy for legalizing loft housing in 1960s. By reviewing literatures on arts districts through the lens of relational place-making, I show that in both cases artists constructed place-frames with the intention of gaining support from city officials, but these place-frames also created conditions for consequences that hurt artists' interests.

Current studies about China's arts districts document the historical trajectories of some famous arts districts, and show that arts districts are at first products of changing state-society relations in the late 1990s. On one hand, there was a remaking of social contract between state 
entities and artists, which led to increasing numbers of freelance artists who needed suitable living-working places $(\mathrm{Gu}, 2012)$. And on the other hand, managers of some state-owned enterprises (SOEs) that went bankrupt during economic reform sought to preserve and rent out vacant factory properties (Currier, 2012; Zhong, 2009). The arrival of artists contributed to protecting the properties from further deterioration and providing income to the enterprises, thus to some extent was initially welcomed by the factory managers (Gu, 2012; Zhong, 2009; 2012). However, the contracts between factory managers and artists were very vulnerable, especially when alternative, and more desirable - as viewed by local governments or factory managers uses of the land became possible (Currier, 2008; 2012; Zhong, 2009; 2012). Attempts to preserve arts districts were usually initiated by artists who drew on international supports to raise their voices. The achievement of such movements, nevertheless, was not brought by international actors, but "won from within the Chinese political system" (Currier, 2012, 190). Research finds that in the efforts to preserve arts districts, it was often local scholars who played an important role in convincing local governments that arts districts are valuable cultural assets for cities, especially for the image of a global city (Chou, 2012; Currier, 2012; Zhong, 2009; 2012).

Viewing the conflicts between artists and factory managers from the relational placemaking perspective, it is clear that place-framing was utilized when artists faced competitions over land use, and local governments were actively sought by artists and scholars for support. In fact, it can be argued that place-frames in these cases were mostly constructed with the purpose of enrolling local governments: arts districts were presented as places that can bring various benefits to cities. Similarly, although spatially and temporally far away from these cases in China, artists in the 1960s SoHo when facing evictions and disputes over their rights to use lofts as residences and studios (due to the illegality of such uses), mobilized place-frames that 
emphasized the roles of the arts district in contributing to the cultural economy of the city and in attracting real estate investment (along with other place-making actions such as organizing artists strikes and art festivals) to lobby for zoning changes and legalizing SoHo loft housing (Shkuda, 2015; Zukin, 1989). Both the case of Chinese arts districts and that of SoHo show that the need of gaining key actors' support can affect how place-frames are constructed considerably.

Also in both circumstances, the place-making actions with purposefully constructed place-frames brought certain unforeseen consequences. In SoHo, artists' promotion of loft housing, in conjunction with societal valorization of art, led to higher real estate interests in the area and influx of middle-class residents who eventually displaced many artists from loft housing (Shkuda, 2015; Smith, 1996; Zukin, 1989). And in China, the processes of enrolling local governments for their support turn them into one of the actors in shaping arts districts, but their actions often do not align with artists' interests. Studies identify two main mechanisms (also place-frames) through which local governments affect arts districts: one is to brand and promote these places as tourist destinations, and the other is to define arts districts as "creative/cultural industry clusters" (Currier, 2012; Gu, 2012; Wang, 2009; Zhong, 2009). These two approaches combined arguably create conditions that cause displacement of artists from arts districts: while the former raises the attraction of arts districts to the broader population and hence the interests of commercial tenants in these places, the loose policy definition of the latter allows the arrival of commercial tenants at arts districts and commercialization of arts districts ( $\mathrm{O}^{\prime} \mathrm{Connor}$ and $\mathrm{Gu}$, 2014; Zheng, 2010).

Viewing artists' actions regarding disputes over uses and claims of places through the lens of relational place-making shows that the need for the support of politically powerful actors affects, if not motivates, the ways that place-frames are constructed. These place-frames 
subsequently shape future possibilities for place-making: elements of place-frames may attract new actors, or new actors may get involved in place-making during processes of enrolling and negotiations, and these actors would play a role in place-making through bringing their own place-bundles and/or constructing their own place-frames, both of which are conditioned by the positionalities of the actors as well as multi-scalar and multi-temporal interconnections of economic, social, and political dynamics (including the preceding place-making). Building on this idea, in the rest of this paper, I draw on data collected through field research at an arts district in Beijing to provide a more detailed analysis of how a particular place-frame is constructed under the condition of needing to gain support from particular actor(s), and how this place-frame and the enrolling of new actor(s) shape future place-making and lead to unintended results of the place-frame that is constructed in the first place.

\section{Case background and data collection}

The case examined in this study is the 798 arts district in Beijing. It is based in a factory compound in northeastern part of the city (Figure 1). The compound originally was 718 Joint Factory, which consisted of 706, 707, 718, 797, and 798 factories. The factory became Beijing Seven Stars North China Electronic Technology Group LLC (shortened as Seven Stars Group) in 2000 during reform of the ownership and financial structure of state-owned enterprises (SOEs). Although the compound is now named the 798 arts district, officially "798 cultural and creative industry cluster", part of the compound is still used for industrial production of electronics, while parts of it are subject to increasing commercialization with emergence of stores, cafes, 
restaurants, and a hotel. The compound and the business or gallery spaces in it are now often rented as venues of commercial campaigns, fashion shows, reality TV shows, and so on.

Major stakeholders that construct and mobilize place-frames in this case include the landlord, arts communities, and municipal and district governments. The landlord of 798 is the factory (Seven Stars Group), represented by the managers. For the focus of this paper, arts communities (artists, galleries, and art institutions) can be divided into those who choose to work with local governments, and those who choose not to. Even though usually only the former participates in place-framing, some of the place-bundles that are conceptualized by members of the latter are also included in the discussion below. Beijing Municipal Government and the government of Chaoyang district of Beijing are the two major levels of local governments in this case. The municipal government influences arts districts in Beijing through policies and planning, whereas district governments are usually the ones that carry out direct and specific tasks of administering the arts districts.

Data for this paper is collected through field research in Beijing between September 2014 and February 2015, from semi-structured interviews with 25 artists/galleries/arts institutions, 2 factory managers, and 5 government agencies and representatives ${ }^{2}$ policy and planning documents and proposals issued by Beijing Municipal Government (131) and Chaoyang district government (25) during 2004-2014; and site observations. Among all interviews, three were conducted in English (with artists) and the rest were conducted in Chinese and translated by the author. All policy and planning documents and proposals are originally written in Chinese and translated for this paper by the author. 
Figure 1 Location of 798 arts district in Beijing

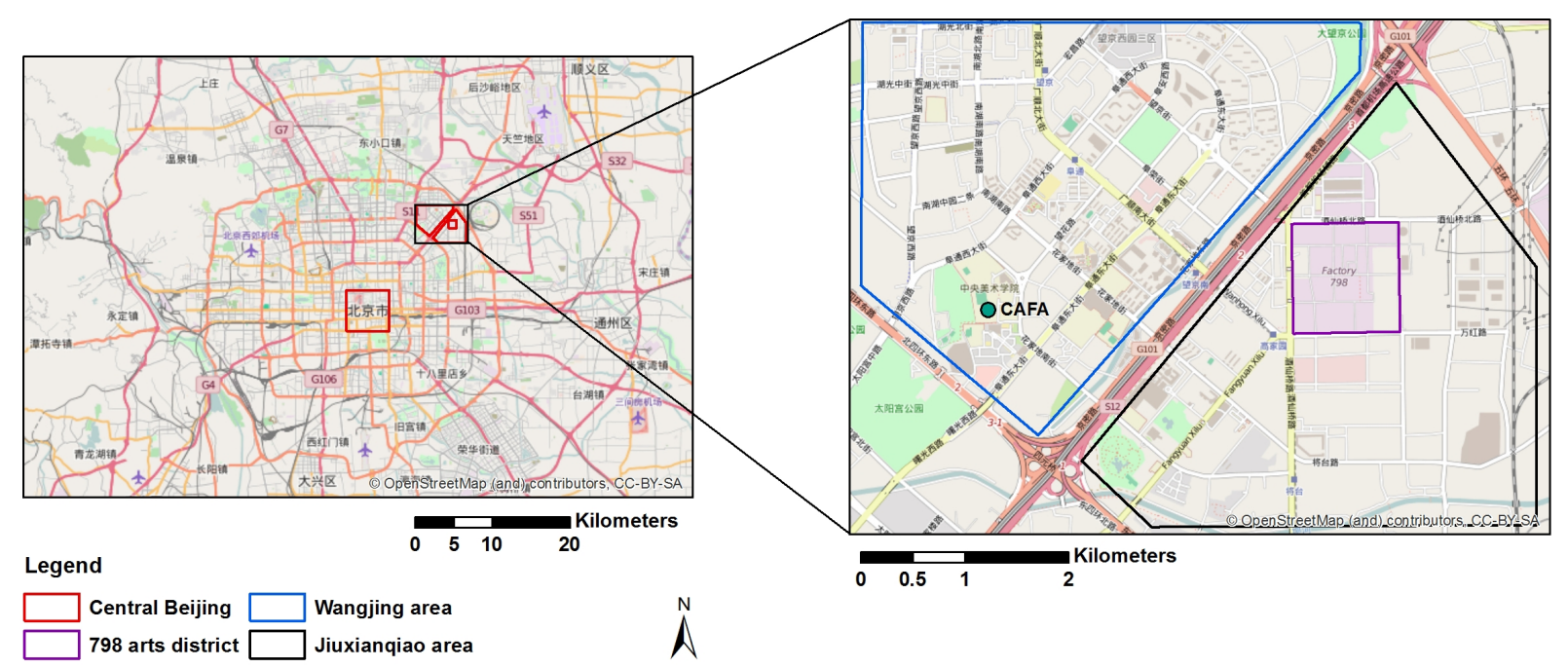

\section{The making and remaking of $\mathbf{7 9 8}$ arts district}

Artists' arrival and conflicts with factory mangers

The relocation of Central Academy of Fine Arts (CAFA) is often deemed the key factor in turning the compound of 718 Joint Factory into an arts district. In 1995, CAFA was relocated from its original campus in Beijing's urban center to the then "frontier of urbanization", Wangjing area (Figure 1). Before moving into its new location, CAFA had a temporary campus close to the 718 Joint Factory. Due to space limitations in the temporary campus, teachers and students of the Sculpture Department decided to find alternative studio space for making large sculptures and statues, especially sculptures for the celebration of the 50th anniversary of PRC in 1999 (Shu, 2004). Under these circumstances, they encountered no obstacles to renting factory floor space as studios in the 718 Joint Factory, and some of the teachers, also well-known sculptors, continued using such space as personal or teaching studios after the special project had 
concluded (CCTV, 2011; Kiang, 2004). The presence of these artists was the initial point of the growth of an art community in this factory compound.

The reason there was space available for renting in the factory was that around the same time the factory was going through the reform launched on SOEs, which resulted in shrinking scale of production, workers being laid off, and vacant factory buildings (Garnaut et al., 2005). In 2000, 718 Joint Factory finished the transformation into Seven Stars Group, and managers faced the problem of finding additional sources of income to meet their financial obligations, especially to compensate laid off employees. ${ }^{3}$ Land was perceived as the asset for generating income for the factory, and the managers chose the strategy of "land use replacement (tudi zhihuan)", a practice commonly adopted by reformed SOEs through which the land parcels that were originally allocated to them for free were sold to developers to finance the relocations of factories to the urban periphery $(\mathrm{Hu}, 2015,2807)$ :

The plan was to either relocate the whole factory to a new industrial park, or consolidate all the existing assembly lines into a smaller area in the compound, and sold the land as part of the 'Electronics City'. The idea was there for a long time, and we were only waiting for finalizing the plan (factory manager, F-1). ${ }^{4}$

Before selling the land, factory managers decided to open the rental market of vacant factory buildings temporarily. Every factory was given certain autonomy in leasing unused factory floor space through its own property management office and was required to meet a minimum level in the amount of monthly rent collected.

Artists, mainly sculptors, who were already renting factory floor space as studios, facilitated the distribution of this information to arts communities, and artists who had experiences abroad were attracted to these factories for their similarities with post-industrial art spaces in New York City or Berlin: 
I started looking for studio in 2001 and planned to choose a factory since the beginning, because it tends to be more spacious and cheaper, and have better lighting with big windows and doors. I had also seen places like that in SoHo and Berlin. X took me to 798 in January 2002, and we met with $\mathrm{Y}$, who was working in the property management office of 798 . Back then, each factory rented out its own buildings, and I signed a lease with 798 (artist, A-1).

While most of the factories were cautious in leasing former factory floor space to artists, who were, and still are, often perceived as a "problematic group" in Chinese society, people of the 798 factory decided to give it a try since artists were seemingly the only tenants that they could attract at that moment:

We weren't sure what would happen. No one knew. At first all the leases were only signed for two years. We had to write a report to the head of the Group, in case they were not happy with what we were doing. The report was titled "Two stars shining together: An art town emerged in a factory town"... Actually, there was nothing to worry about. This is a factory compound, if anything happened, we could just shut the door... At least, we accomplished the task [of collecting rent] (factory manager, F-1).

Thus, almost accidentally, 798 factory became the starting point of the phenomenal emergence of artists in this former military industrial compound, and became the symbol of the whole compound. By 2003, suitable spaces in the 798 factory were almost all taken. With the growing number of artists seeking former factory floor space, other factories began taking them in as tenants. Since plan of the future use of the compound was already made, the managers had never viewed renting as a long-term plan but a temporary solution, and artists were told what would happen to the factories when they came and signed their leases for only 2-3 years. Nevertheless, many of them invested into their studios, brought in galleries and clubs, and publicized exhibitions there. 
To factory managers, the compound is a factory asset, which has potentially good value in the urban land market and whose use is solely subject to their will. But to artists who chose 798 in the early 2000s, the compound was "the core of Chinese contemporary art" (artist, A-2), “an edgy and authentic arts district" (artist, A-3), "where China's art market is" (artist, A-4), and "post-industrial space that can be turned into an internationally renowned arts district" (artist, A1). Clashes between the perception of the factory managers and that of the artists finally manifested in conflicts around an event named "Reconstructing 798", which was organized by a group of artists in April 2003. The event name irritated the factory managers, who perceived themselves as the owner of the factory and artists as merely the tenants who have no right in either reconstructing the factory or claiming the name 798, especially when manufacturing was still going on in the factory:

The factory is still here. It has always been here. Production has always been going on, only that the scale is much smaller. It's not accurate to say that it was obsolete (factory manager, F-1).

In the spring of 2003, before the outbreak of SARS in Beijing, Seven Stars Group told us to stop using '798'. Then we chose 'Dashanzi'. So it was called 'Dashanzi arts district' since then till 2006 (artist, A-1).

Partly because of the planned timeline of getting the land ready for sell and partly driven by the discontent towards artists, Seven Stars Group suspended leasing available spaces and demolished some of the empty factory buildings in early 2004.

Artists' place-framing and alliance building

Artists were afraid of being pushed out and decided to take action in saving their studios and exhibition spaces. A motion was submitted to Beijing Municipal People's Congress in 2004 by 
an artist, Li Xiangqun, who served as the representative of the art community of 798 . This

motion demonstrates how artists constructed the arts district place-frame strategically. First, the

compound is presented as an "industrial heritage" that has unique architectural and historical

values, thus should be preserved:

Preserve an industrial heritage! Preserve a growing arts district! ...Besides the fact that the factory received technical support from 22 factories of East Germany in the early stage of production, the factory buildings were also designed by 55 German experts, who adopted the then most advanced construction techniques and Bauhaus design concepts. These buildings are beautiful and magnificent. They are rare treasures of modern industrial architecture...

Considering the size and integrity of the currently preserved area, as this kind of architecture, 718 is one of the few still left in the whole world. And artists transformed these buildings... While preserving the original state of the architecture as much as possible, artists also revitalized the buildings and made them more suitable for living and for artistic or other kinds of activities... Besides its importance in China's industrial history, this area is also historically significant in terms of being witness to the friendship between people of China and Germany, and to the era of the socialist alliance (Li, 2004).

This proposition was further strengthened after the then Chancellor of Germany, Gerhard

Schroder, visited the compound in 2004 (interview with artist, A-3).

Secondly, the arts district is depicted as an important component in building an image of

global city for Beijing, and thus needs to be protected and supported:

... Besides attracting artists and visitors from all over the world, more importantly, the arts district attracts global attentions and investment. The size of the area that can be used as both arts and high-end commercial district could have been much larger than what it is now, if the factory hadn't stopped leasing spaces since April 2004 due to its original plan of demolition and construction. As everyone knows, Beijing was selected as one of the twelve world cities by Newsweek in 2003 for the first time, and the existence and development of this arts district was listed as the key reason for selecting Beijing, for it proves the ability and potentiality of Beijing as a world capital... Beijing is going to host the Olympic Games in 2008, and what kind of image of the city are we going to show to the world? A construction site or the representation of a diverse and open society? $(\mathrm{Li}, 2004)$ 
By weaving elements of multiple temporal-scalar threads together into the place-frame, the arts district is presented as a place that is significant to the city (building the image), the state (witness to the history), and the world (unique architecture). What is missing in the place-frame, however, is the kind of place that the arts district is to the arts and artists. This omission is an intentional choice based on the status of contemporary art and artists in China. The Chinese state's acceptance and tolerance of contemporary art is very limited, due to the fact that most contemporary artwork engages with social and political critique and tends to express political opinions that deviate from those state-approved ones (Wu, 2010; Zhang, 2014). Under such circumstance, the gatherings of contemporary artists are often deemed as potentially problematic by governmental bodies and subject to harsh scrutiny (Xiong, 2011; Zhang, 2014). Thus, the arts district place-frame is clearly a strategic construction by artists with the goal of enrolling the municipal government as an ally: artists picked and emphasized a few points that could potentially be accepted and agreed by the municipal government in order to turn the government into supporter of the place-frame, and ultimately, to keep the compound as an arts district. Artists' place-frame is both a constructed narrative that articulates the demands of the artists (to preserve the arts district) and a negotiation strategy that purposefully highlights the benefits of the arts district to the government (historical value and city image) and downplays the "troubling" aspects (contemporary art and artists).

It is hard to tell which element(s) played the key role, but artists' goal of deploying this arts district place-frame was achieved: both municipal and district governments sent personnel to research the case, and in 2006, the compound was named 798 arts district and was institutionalized as an official "cultural and creative industry cluster" (Xu, 2006). The naming, however, only serves a symbolic role of granting a seemingly unitary identity to the place, as a 
sign of the resolution of the conflicts. 798 still means different things (places) to different people. There are always multiple place-bundles at this one locus, conceptualized by actors situated in different positionalities. Nevertheless, the naming to some extent affected the strategies adopted by stakeholders in subsequent place-contestations and place-framing/making. The place-frames that they construct, whatever the goals are, have to be subsumed under the overarching "arts district" narrative, thus can only be presented as different interpretations of "arts district". In this sense, the naming serves as a force that subjects place-frames to a claim of coherence and unity (Pierce and Martin, 2015, 1289).

Evolving place-frames and the (re)making of 798 arts district

To Seven Stars Group, 798 is still its asset - at least the land and properties are still owned by the factory - but the framing was altered slightly after 2006. Instead of claiming ownership directly and explicitly, factory managers constructed a new narrative of the factory, within which both production of electronics and development of cultural and creative industry are said to be the business of Seven Stars Group:

Beijing Seven Stars North China Electronic Technology Group LLC (shortened as Seven Stars Group) ... is a high-tech company that is reorganized based on modern enterprise system. Seven Stars Group specializes in the R\&D, manufacturing, and marketing of special electronic equipment, electronic components and parts, and electronic materials, as well as is devoted to developing cultural and creative industry based in 798 arts district (UCCA, 2013).

In this way, 798 is defined as the place where Seven Stars Group develops the part of its business called cultural and creative industry. Factory managers' role as the landlord is subtly implied, 
and without challenging the officially designated role of 798, their power of choosing tenants, although circumscribed, maintains.

The municipal government also has its own framing of 798 arts district, which was at first mainly defined as a tourist attraction, along with other cultural and creative industry clusters. In two Plans issued by the Beijing Municipal Government (BMG) during 2007-2008, one on the development of cultural and creative industry (BMG, 2007) and the other on the development of tourism (BMG, 2008), the need of strengthening the function of cultural and creative industry clusters for tourism is particularly emphasized:

Plan and develop 798 arts district and Songzhuang artist village as new type of cultural tourist attractions. Cultivate the tourism function of cultural and creative industry clusters, and turn them into thriving cultural tourism projects of Beijing (BMG, 2007).

Speed up the development of ancillary facilities for tourism based on the standard of national 5Alevel tourist destination in... cultural and creative industry clusters... (BMG, 2008).

This tourist attraction place-frame was constructed through strategically drawing on and twisting elements of the arts district place-frame that was created by artists earlier. First, tourism is considered as a key approach for building and strengthening the image of the city. Since 798 is depicted as a place that helps Beijing to build a world/global city image, attracts attention and visitors globally, and is especially good for the image that Beijing wanted to present to the world before the Olympic Games, it is then easily justifiable for the municipal government to define the arts district as a tourist attraction. The Chaoyang district government also supports the framing of 798 as a tourist attraction. In 2008, right before the Olympic Games, one district official made a famous statement that is still often quoted when people talk about 798: "What are worth attention in Beijing? I hope everyone would remember our slogan: The Great Wall, Peking duck, 798” (Shen, 2009). Second, the tourist attraction place-frame also draws on the "industrial heritage" 
component of the previous arts district place-frame. As a heritage, then it is "normal" and justifiable for it to be developed for tourism, like many other cultural heritages:

In recent years, industrial tourism is a rapidly rising niche market in Beijing's tourism market. By the end of 2007, Beijing has... developed several internationally well-known tourist attractions, including 798 and 751, which attracted millions of tourists and visitors... The history of industrialization is an important part of Beijing's urban history. ...Former industrial buildings and equipment are now precious heritages of history and culture, and are redeveloped and reused under the condition of conservation... (BMBIA, 2008).

Industrial heritages are historical remains that are closely connected with history of industrialization, have historical, social and cultural, aesthetic, scientific, and reusable values, and are important parts of cultural heritage (BMBIA, 2009).

Once the tourist attraction place-frame was constructed, it developed into one that characterizes 798 arts district as an art-themed area for leisure and entertainment, fashion and cultural consumption, and "experience". In several Opinions ${ }^{6}$ and Plans issued by the municipal government on developing tourism (BMCTD, 2011; BMG, 2010), urban industry (BMCEIT, 2011), and cultural industry (BMBC, 2013), 798 arts district and cultural and creative industry clusters in general are not only defined as themed leisure areas but also encouraged to develop into entertainment and commercial complexes:

Actively foster the integration of tourism industry and cultural industry... promote the building and development of culture clusters that would integrate performance, entertainment, film industry, dining, hotel, and fashion consumption... (BMG, 2010).

Focus on the integration between cultural and creative space and commercial and business activities... Encourage cultural and creative industry districts to set up areas for experiencing culture consumption or large complexes integrating culture and commerce, thus to become onestop that provides all services for creating, developing, experiencing, and consuming... Promote formation of clusters for producing and consuming special cultural products in cultural and creative industry districts, in order to provide special consumption experiences, attract consumers, facilitate interactions between production and consumption of culture, build new destinations for cultural consumption... (BMBC, 2013). 
This shift is understandable given that tourism is associated with leisure, entertainment, consumption, and experience. By 2014, the official designation of 798 had transformed from "cultural tourist attraction" (BMG, 2007) to "district of fashion and creative functions" (BMG, 2014). By explicitly drawing on elements of the arts district place-frame constructed by the artists, the municipal government's earlier tourist attraction place-frame is easily legitimized; and by twisting elements of "city image" and "heritage" and realigning them with tourism, this placeframe facilitates the change of focus to "entertainment and consumption" in the framing of arts district. Such framing is rooted in the political agenda that the municipal government has in regard to arts districts. The municipal government's framing of 798 focuses on aspects of tourism, leisure, consumption, and fashion, which functions to dilute the association of art with the arts district and depoliticize the place (Zhang, 2016). To the municipal and district governments, 798 as an arts district for art is not producing any tangible, economic value (interview with government representative, G-1), but is more a burden, because of concerns of cultural security:

The government won't truly support 798 as an arts district, because of the issue of art and ideology (factory manager, F-2).

Contemporary art is mainly about social critiques, so the government agency and representatives that govern 798 have to be based in the department in charge of ideological control (government representative, G-2).

We go there fairly often. If there were a painting that I think is not appropriate to show, I would ask the gallery to put it somewhere else. Some implicit social critique is allowed, but you can't use images of the state leaders (government representative, G-3).

Once the government stepped in, it began to have more and more control on the content. Staff of the management office would walk in whenever there is a new exhibition, and would point to artworks that they think are problematic and ask us to put those away (artist, A-5). 
The tourist attraction and subsequent place-frames serve the role of displacing "art" from the narrative of arts district, and the place-frame that was constructed by artists in the previous placecontestation provided the necessary elements for such displacement. In their efforts to preserve and legitimatize the use of the factory compound as an arts district, artists intentionally concealed the functions of 798 arts district as a place where artwork is made, displayed, and circulated in the place-frame, in order to present the arts district as a safe and unproblematic place to the municipal government. "Arts" as a (supposedly key) component of the arts district is implied in the name, and the primary function of the arts district therefore ought to be serving the arts communities. However, the art part has been glossed over in official rhetoric since the very inception of 798 as an officially recognized arts district, partly as a result of the initial arts district place-frame constructed by artists. The necessity of gaining the municipal government's support shaped artists' place-framing practices, which subsequently affected the municipal government's action in place-framing and also provided the necessary elements that the government needs in order to smoothing the change of framing of the arts district. The strategic choice made by artists is understandable given their vulnerable position in uneven power relations with the factory and the municipal government. But in trying to build an alliance with the municipal government, artists' goal of protecting their interests was only achieved in a superficial way, namely keeping the compound from being demolished.

The place-frames mobilized by the municipal government further go hand in hand with the place-frame constructed by Seven Stars Group, and resulted in displacement of artists and art-related uses. As 798 is officially defined as place of leisure and consumption, Seven Stars Group then has its justification to lease the buildings to more commercial, non-art, tenants that can pay higher rent. The power of the factory managers in deciding who can rent the properties is 
not circumscribed much after all, for the label "fashion and creative functions" is so ambiguous that "all traditional entertainment and commercial businesses" (Zheng, 2010, 159) can fall under it (Zhang, 2016):

Restaurants offer creative food (chuangyi canyin), bars serve creative desserts (chuangyi xiaochi), and retail shops sell creative products (chuangyi xiaofei). Under the same logic, a shopping mall may similarly be called a creative industry cluster as all their activities may be attributed to fashion and consumption creativity (Zheng, 2010, 159).

In this way, Seven Stars Group collects more rent, and the municipal government displaces some of its problem, namely art, away from attention and to more remote and marginal areas of the city.

As 798 becomes touristy and commercial, both the discontent of artists and galleries towards Seven Stars Group and the municipal government and their expectations for change are accumulating. Some artists wish the place could return to its "best period" when there was "a good mix of quality galleries, studio lofts, and some beautiful cafes" (artist, A-3). Some others are more realistic on the fact that 798 probably will not be able to turn back into a place for the production of art, namely a district of artist studios. What they wish for are "more quality galleries" (artist, A-6), “adding non-profit public art institutions" (artist, A-7), and "less government intervention" (artist, A-4) in 798 to keep it as the core of exhibiting and circulating contemporary art in China. For those who intend to make a strategic move, a new place-frame is in the process of formation, which, similar to the previous one, is also constructed through mobilizing a few potential points of agreement:

What we propose is to develop an underground area of 798. It will increase the floor area of 798 and can be used for commercial activities. It can even be a shopping mall. The area on the ground can be used only for art, and it will be affordable, because the underground commercial area can 
raise enough rent to support the art area. 798 will then be an "artistic commercial complex" (artist, A-8).

Even as a tourist destination, 798 has a lot of problems. What should be done is some spatial reorganization to highlight the presence of art, while at the same time build some new buildings to increase the floor area to bring in more economic profits, and build an underground parking lot so that tourists can walk comfortably in the district (artist, A-1).

The managers can charge an entry fee at the entrances of the compound. Since 798 attracts so many visitors, the entry fee can be a considerable income, and they can use it to subsidize the rent that galleries pay. In this way, more artists and galleries will be able to afford staying here (artist, A-9).

These individually constructed ideas have yet to be combined and form a new place-frame of 798, but they demonstrate that for the purpose of strategic negotiations, artists probably need to first show that they also see 798 as an artistic tourism/commercial complex, which is a point that is agreed by the municipal government and Seven Stars Group. The goal of artists is to reconfigure the relationship between tourism/commercialization and art in 798 , so that these two are not in competition but benefit from each other. Whether the place-frame is going to be constructed, whether artists' goal will be achieved, and whether it is even possible to have a balanced and mutually beneficial relationship between commerce and art in an arts district are still unknown.

\section{Conclusion}

798 arts district is shaped by interconnected discursive strategies (place-framing) of various stakeholders. Their discursive constructions of arts districts are interconnected in the sense that there are common elements being shared and recycled among place-frames of arts districts, but also being twisted and realigned with other elements for different strategic goals. The reason for such a relationship among the place-frames is a strategic move made by artists in their efforts of 
preserving the use of the land as an arts district. As a strategy, artists' construction of the arts district place-frame was based on intentionally selecting elements, concealing the component of "art", and emphasizing points that could be potentially supported by the municipal government. These elements were then reused and reinterpreted in arts district place-frame(s) constructed by the municipal and district governments for their interests, which go hand in hand with that of the factory managers (landlord). The next step taken by the artists is similar to the earlier one, in which they try to (re-)frame the arts district based on "points of agreement" (Pierce et al., 2011, 61). Even though the changes that already happened to 798 demonstrate that this kind of strategy can only serve artists' interests in a superficial way and for a brief period, in the current ongoing place-framing/making practices, there is a sign of bringing "art" into the arts district place-frame that might be constructed by artists, and thus a hope for keeping and even expanding art-related land use in 798. However, as places, arts districts are always contested, whose meanings are multiple, with an uncertain future.

In relational understandings, places are bundles of space-time trajectories configured by individuals (Massey, 1991; 2005; Pierce et al., 2011). Place-making involves constructing placeframes that draw elements from multiple (relatively) individually conceptualized place-bundles towards social and political ends. Such "strategic sharing of place" (Pierce et al., 2011, 60) is result of negotiations among people with shared or similar goals. There are however at least two different types of negotiations that may happen in the processes of place-framing and placemaking: one is the negotiations among people who initiate place-framing in order to make claims over the meaning or/and use of places; and the other is the negotiations among different (collective) actors in the processes of place-making for the purpose of enrolling others as allies of particular place-frames. Van Neste and Martin (2017) point out that in different moments of 
place-framing - naming/blaming, claiming, and practicing - place-frames may go through multiple rounds of re-articulation as a result of the converging or diverging interests or understandings of places among (collective) actors. They suggest that the co-articulation of place-frames and alliance of actors is influenced by the specific power geometry of place politics and that the relations and negotiations between activists and governmental actors tend to be the key for understanding the iterative production of place-frames (Van Neste and Martin, 2017, 11).

The case of 798 arts district examined in this paper shows that when it is necessary to gain the support of particular actors for place-making goals, place-frame is both a narrative of the place that articulates the claims and demands of actors and a discursive strategy that serves for negotiations with potential allies. And when stakeholders are situated in very uneven power relations, the intertwined processes of place-framing and negotiations among actors might involve one side's mobilizations of elements that can potentially be supported by the other side. Certainly, there is always some disconnection between individually conceptualized placebundles and the strategically constructed place-frames. However, when potential points of agreement are intentionally selected into creating a place-frame, the gap between individual place-bundles and the place-frame can be quite big and leave ample room for reinterpretation by stakeholders who are more powerful. In this case, those who construct and mobilize the placeframe for their interests in the first place are put in a vulnerable position, and elements of their place-frame may be hijacked and taken advantage of by other actors in subsequent place-framing and place-making.

This paper points out the necessity of paying attention to the temporality of place-framing and place-making. On one hand, the anticipation or prediction of "the next step" after the initial place-framing, such as enrolling other actors, can affect the construction of place-frames. Thus 
place-framing involves not only elements of various temporal-scalar threads being drawn together into a crafted narrative, but also strategic decision-making due to power relations among different actors. And on the other hand, new place-frames may be produced throughout place conflicts as new issues emerge or new actors join (either through enrollment or being attracted), and elements of previous place-frames may be recycled into new place-frames. Having shared elements among place-frames however does not always suggest a continuation from the previous stage of place-making, as it can also be a strategy for smoothing a change in the direction. These two aspects suggest that a relational understanding of place-framing and place-making needs to consider how different moments of place-making affect the strategies, practices, and results of place-making, namely how both the anticipated future of/in place-making and the past placeframing/making play a role in the dynamic and contested processes of place-framing/making. These aspects also highlight the importance of the relations between activists and governmental actors in place-making. And by attending to the temporality of place-framing and place-making, the relational place-making approach can be more robust for analyzing how place-making practices and place conflicts are shaped by the relationship of citizens to the state, which varies greatly across the world, and become more globally oriented.

\section{References}

Beijing Municipal Bureau of Culture (BMBC), 2013. Opinions on facilitating the integration of culture and business and accelerating development of new type of cultural industry. http://www.chycci.gov.cn/news.aspx?id=5848 Accessed 12 September 2014.

Beijing Municipal Bureau of Industry Advancement (BMBIA), 2008. Guiding opinions of Beijing Municipality on advancing the development of industrial tourism. http://www.creativeindustry.org.cn/policies/bj11.htm Accessed 21 September 2014. Beijing Municipal Bureau of Industry Advancement (BMBIA), 2009. Working guidance of Beijing Municipality on preserving and reusing industrial heritage. http://www.pkulaw.cn/CLI.12.360135 Accessed 18 September 2014. 
Beijing Municipal Commission of Economy and Information Technology (BMCEIT), 2011. Plan of Beijing Municipality on development of urban industries during the time of the Twelfth Five-year Plan. http://zhengwu.beijing.gov.cn/ghxx/sewgh/t1202278.htm Accessed 18 September 2014.

Beijing Municipal Commission of Tourism Development (BMCTD), 2011. Plan of Beijing Municipality on development of tourism industry during the time of the Twelfth Fiveyear Plan. http://zhengwu.beijing.gov.cn/ghxx/sewgh/t1204036.htm Accessed 18 September 2014.

Beijing Municipal Government (BMG), 2007. Plan of Beijing Municipality on the development of cultural and creative industry during the time of the Eleventh Five-year Plan. http://zhengwu.beijing.gov.cn/ghxx/sywgh/t833175.htm Accessed 9 January 2014.

Beijing Municipal Government (BMG), 2008. Opinions of the Beijing Municipal Government on fully advancing the development of tourism industry of Beijing Municipality. http://www.pkulaw.cn/CLI.12.267543 Accessed 9 January 2014.

Beijing Municipal Government (BMG), 2010. Opinions of the Beijing Municipal Government on acting in the spirit of and implementing the document issued by the State Council on speeding up development of tourism. http://www.pkulaw.cn/CLI.12.461462 Accessed 2 October 2014.

Beijing Municipal Government (BMG), 2014. Notice of the Beijing Municipal Government on issuing 'Plan of Beijing Municipality on constructing and developing cultural and creative industry function districts (2014-2020)' and 'Plan of Beijing Municipality on improving cultural and creative industry (2014-2020). http://www.pkulaw.cn/CLI.12.872265 Accessed 2 October 2014.

China Central Television (CCTV), 2011. Portrait of the Times: 798 http://tv.cntv.cn/videoset/C23028 Accessed 15 December 2014.

Chou, T.-L., 2012. Creative space, cultural industry clusters, and participation of the state in Beijing. Eurasian Geography and Economics 53 (2), 197-215.

Currier, J., 2008. Art and power in the new China: an exploration of Beijing's 798 district and its implications for contemporary urbanism. Town Planning Review 79 (2-3), 237-265.

Currier, J., 2012. Selling place through art: the creation and establishment of Beijing's 798 Art District. In: Daniels, P. W., Ho, K. C., Hutton, T. A. (Eds.) New Economic Spaces in Asian Cities: From Industrial Restructuring to the Cultural Turn. Routledge, London, pp. 184-201.

Davine, T., Lawhon, M., Pierce, J., 2017. Place-making at a national scale: framing tar sands extraction as "Canadian" in The Globe and Mail. The Canadian Geographer 61 (3), 428439.

Deutsche, R., Ryan, C. G., 1984. The fine arts of gentrification. October 31 (Winter), 91-111.

Garnaut, R., Song, L., Tenev, S., Yao, Y., 2005. China's Ownership Transformation: Process, Outcomes, Prospects. World Bank Group, Washington DC.

$\mathrm{Gu}, \mathrm{X} ., 2012$. The art of re-industrialisation in Shanghai. Culture Unbound: Journal of Current Cultural Research 4, 193-211.

Hu, F. Z. Y., 2015. Industrial capitalisation and spatial transformation in Chinese cities: strategic repositioning, state-owned enterprise capitalisation, and the reproduction of urban space in Beijing. Urban Studies 52 (15), 2799-2821. 
Kiang, K. M., 2004. Introduction: a new vocabulary. In: Huang, R. (Ed.) Beijing 798:

Reflections on Art, Architecture and Society in China. Timezone 8 Limited and Thinking Hands, Beijing, pp. 4-9.

$\mathrm{Li}, \mathrm{X}$., 2004. Motion on protecting and developing the cultural industry zone in the area of "718 Joint Factory".

Mars, N., 2014. Data of 798 based on interview with Vice Director Li, Cultural Office of Seven Stars Group, July 30, 2014. http://supersatellites.burb.tv/view/Entry:500?node=798 and the CREATIVE CLUSTE R CONUNDRUM Accessed 7 February 72015.

Martin, D. G., 2003. "Place-framing" as place-making: constituting a neighborhood for organizing an activism. Annals of the Association of American Geographers 93 (3), 730 750.

Massey, D., 1991. A global sense of place. Marxism Today June, 24-29.

Massey, D., 2005. For Space. Sage, New York.

O'Connor, J., Gu, X., 2014. Creative industry clusters in Shanghai: a success story? International Journal of Cultural Policy 20 (1), 1-20.

Pierce, J., Martin, D. G., Murphy, J. T., 2011. Relational place-making: the networked politics of place. Transactions of the Institute of British Geographers 36(1), 54-70.

Pierce, J., Martin, D. G., 2015. Placing Lefebvre. Antipode 47 (5), 1279-1299.

Pierce, J., Williams, O. R. and Martin, D. G., 2016. Rights in places: an analytical extension of the right to the city. Geoforum 70, 79-88.

Shen, Z .,2009. 798, discover the true meaning of art tourism. China Tourism News August 24, 2009. http://www.ctnews.com.cn/lybgb/2009-08/24/content_663685.htm Accessed 5 September 2015.

Shkuda, A., 2015. The artist as developer and advocate: real estate and public policy in SoHo, New York. Journal of Urban History, 41 (6), 999-1016.

Shu, K., 2004. “798 factory” and urban morphology. Life Weekly May 19, 2004. http://www.lifeweek.com.cn/2004/0519/8734.shtml Accessed 19 December 2014.

Smith, N., 1996. The New Urban Frontier: Gentrification and the Revanchist City. Routledge, London.

Ullens Center for Contemporary Art (UCCA), 2013. Announcement: Ullens Center for Contemporary Art renewed its lease with Seven Stars Group. http://ucca.org.cn/program/ucca-sstg/ Accessed 15 October 2013.

Van Neste, S. L., Martin, D. G., 2017. Place-framing against automobility in Montreal. Transactions of the Institute of British Geographers doi: 10.1111/tran.12198

Wang, J., 2009. "Art in capital": Shaping distinctiveness in a culture-led urban regeneration project in Red Town, Shanghai. Cities 26 (6), 318-330.

Wu, H., 2010. Contemporary Chinese Art: Primary Documents. The Museum of Modern Art, New York.

Xiong, Y., 2011. Research on Yuanmingyuan artists' village. Unpublished PhD thesis. Department of Sociology, Peking University, Beijing.

$\mathrm{Xu}, \mathrm{F} ., 2$ 2006. Ten districts cluster "Creative Beijing” together. People's Daily December 15, 2006. http://58.68.146.102/rmrb/20061215/11 Accessed 5 September 2015.

Zhang, A. Y. 2016. Arts districts or art-themed parks: arts districts repurposed by/for Chinese government. In: Wang, J., Oakes, T., Yang, Y. (Eds.) Making Cultural Cities in Asia: 
Mobility, Assemblage, and the Politics of Aspirational Urbanism. Routledge, London, pp. 69-79.

Zhang, Y., 2014. Governing art districts: state control and cultural production in contemporary China. The China Quarterly 219, 827-848.

Zheng, J., 2010. The "entrepreneurial state" in "creative industry cluster" development in Shanghai. Journal of Urban Affairs 32 (2), 143-170.

Zhong, S., 2009. From fabrics to fine arts: urban restructuring and the formation of an art district in Shanghai. Critical Planning 16, 119-137.

Zhong, S., 2012. New economic space, new social relations: M50 and Shanghai's new art world in the making. In: Daniels, P. W., Ho, K. C., Hutton, T. A. (Eds.) New Economic Spaces in Asian Cities: From Industrial Restructuring to the Cultural Turn. Routledge, London, pp. 166-183.

Zhongguancun Technology Park Managing Committee (ZTPMC), 2008. Chorography of Zhongguancun Technology Park. Beijing Publishing House, Beijing.

Zukin, S., 1989. Loft Living: Culture and Capital in Urban Change. Rutgers University Press, New York. 
${ }^{1}$ I thank one anonymous reviewer for Geoforum for bringing this point to my attention.

${ }^{2}$ Each interviewee in this article is identified by the use of prefix and number. " $\mathrm{A}$ " indicates artists, galleries, and arts institutions, "F" indicates factory managers, and "G" indicates government agencies and representatives.

${ }^{3}$ The exact number of layoffs is unclear. According to one source, the factory laid off around 15,000 of its 20,000 workers (Currier 2008, 242). Another source, based on an interview with a factory manager in 2014, presents that Seven Stars Group now employs around 6,000 people (300 in the branch of managing the arts district, and the rest in the production of electronics), and the former SOE has 15,000 retired workers and 4,000 that were laid off (Mars 2014).

4 "Electronics City" is a project constructed in the area where several SOEs that specialized in production of electronics concentrate. As a special project aimed at reviving the area, it received tax break and exemption from turning land conveyance income (tudi churang jin) to the municipal government (ZTPMC 2008, 134). Thus for SOEs that sold land (through "land use replacement") under the title of this project, they could keep their income instead of turning a portion of it to the municipal government.

${ }^{5}$ Dashanzi was how the area commonly referred to back then, thus a more neutral naming for the arts district.

${ }^{6}$ Opinions is a type of policy document issued as guidance on how to implement certain policy or plan. 